\title{
Bifurcation structure of adaptation versus depolarization block
}

\author{
Kun Qian*, Marco Antonio Huertas Chacon, Carmen Canavier \\ From Twenty First Annual Computational Neuroscience Meeting: CNS*2012 \\ Decatur, GA, USA. 21-26 July 2012
}

Midbrain dopamine neurons fire in a pacemaker-like fashion in vitro where they are deprived of most afferent input. In vivo, these neurons can emit a burst of action potentials with fast $(\sim 50 \mathrm{~Hz})$ frequencies [1]. However, simple somatic depolarization of these neurons does not elicit such rapid firing because the neurons cease firing at levels of depolarizing somatic current injection stronger than those that elicit repetitive firing at about $10 \mathrm{~Hz}$ [2]. Here we argue that in the case of simple somatic current injection, firing ceases due to adaptation rather than depolarization block. We hypothesize that the primary adaptation mechanism is the slow inactivation of the fast sodium current [3], which causes the spike threshold to become more depolarized with each spike until spiking fails. We contrast the bifurcation structure of a simple 3 variable model that ceases to fire via this mechanism with a two variable model that fails by going into depolarization block. In both cases, spontaneous firing is characterized by an $\mathrm{N}$ shaped voltage nullcline with two stable branches. For the depolarization block, firing ceases when the fixed point moves from the unstable to the stable branch at the knee of the nullcline (Fig.1). The action potentials decrease in amplitude both at the peak and the trough, and the resulting stable
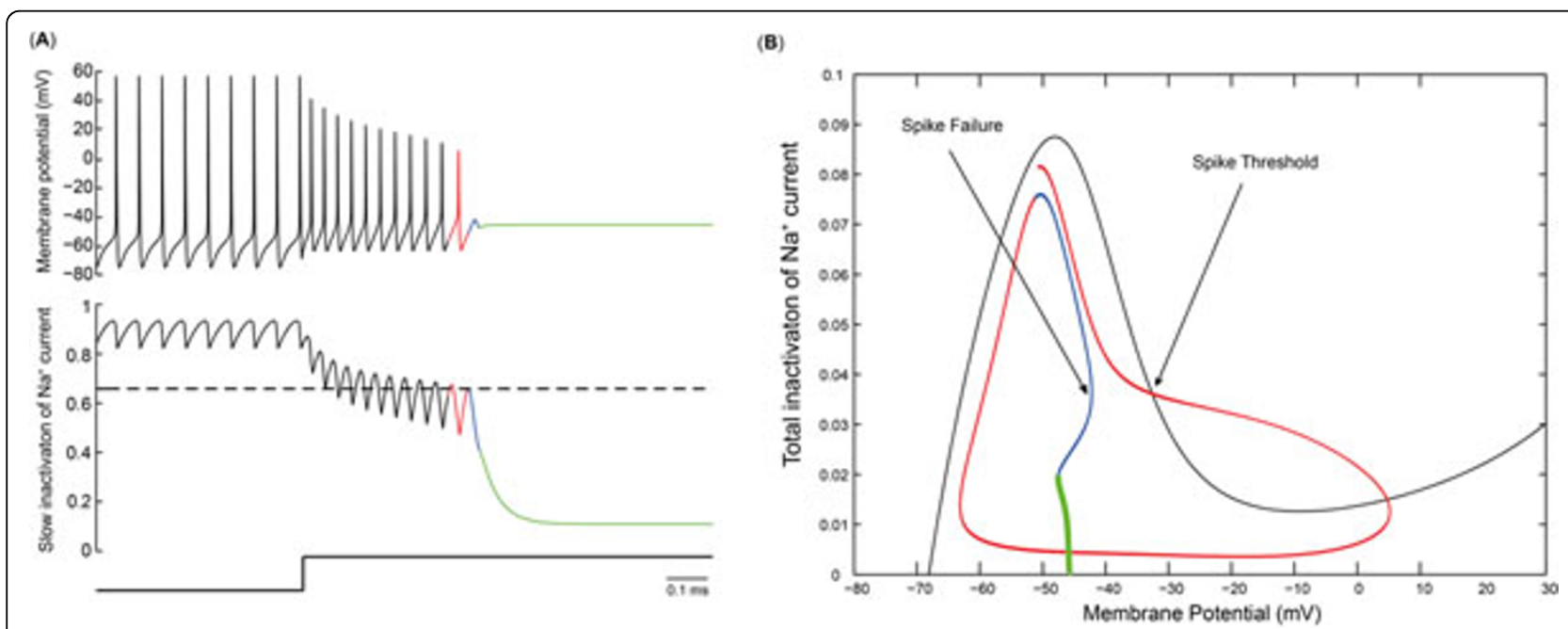

Figure 1 Spike Failure via Adaptation. (A) Time course of the membrane potential (top) and slow $\mathrm{Na}^{+}$channel inactivation, middle), during spike failure after a depolarizing current step (bottom). (B) Phase plane for fast/slow analysis. The $\mathrm{N}$ shaped voltage nullcline (black curve) is calculated at a constant value of slow channel inactivation corresponding to spike failure (dashed line in panel (A)). The middle branch is the effective spike threshold. The red trajectory corresponding to the red waveform in the left two traces exceeds this threshold but not the blue one.

\footnotetext{
* Correspondence: kqian@lsuhsc.edu

Neuroscience Center of Excellence, Louisiana State University Health Science Center, New Orleans, LA, USA
} 
potential is much more depolarized than the spike threshold for the adaptation case. In contrast, for the adaptation case, only the peaks of the action potential decrease slightly, and the final stable potential is at the spike threshold. As slow inactivation proceeds, the voltage nullcline loses the unstable middle branch, and the two stable branches merge. Spiking fails when the trajectory no longer crosses the unstable middle branch (the spike threshold) because the increasing ISI length allows for more fast inactivation. The two mechanisms can be differentiated experimentally: an additional depolarizing square pulse of current applied just after the last spike should evoke an additional action potential for adaptation, but not depolarization block.

Published: 16 July 2012

\section{References}

1. Hyland Bl, Reynolds JN, Hay J, Perk CG, Miller R: Firing modes of midbrain dopamine cells in the freely moving rat. Neuroscience 2002, 114(2):475-492.

2. Richards $C D$, Shiroyama T, Kitai ST: Electrophysiological and immunocytochemical characterization of GABA and dopamine neurons in the substantia nigra of the rat. Neuroscience 1997, 80(2):545-57.

3. Ding S, Wei W, Zhou FM: Molecular and functional differences in voltageactivated sodium currents between GABA projection neurons and dopamine neurons in the substantia nigra. J Neurophysiol 2011, 106(6):3019-34.

doi:10.1186/1471-2202-13-S1-P169

Cite this article as: Qian et al:: Bifurcation structure of adaptation versus depolarization block. BMC Neuroscience 2012 13(Suppl 1):P169.

\section{Submit your next manuscript to BioMed Central} and take full advantage of:

- Convenient online submission

- Thorough peer review

- No space constraints or color figure charges

- Immediate publication on acceptance

- Inclusion in PubMed, CAS, Scopus and Google Scholar

- Research which is freely available for redistribution

Submit your manuscript at www biomedcentral.com/submit 